\title{
Prevalence and correlates of attention deficit hyperactivity disorder in obsessive- compulsive disorder patients
}

\author{
Lamis Ibrahim*, Wail Abouhendy, Nelly Raafat and Amira Ahmed Fouad
}

\begin{abstract}
Background: High rates of history of childhood attention deficit hyperactivity disorder (ADHD) symptoms have been found in obsessive-compulsive disorder (OCD) adults. Both, when comorbid, cause the clinical course to be unfavorable, more susceptibility to substance use, and a bad response to treatment. We planned to assess the impact of childhood ADHD symptoms on OCD adults and the effect of this on clinical characteristics and comorbidities of the disorder.

Results: Our cross-sectional investigation uncovered that 44\% of the OCD patients had childhood ADHD symptoms. Patients with childhood ADHD manifestations with at present grown-up ADHD had more elevated amounts of depression, anxiety, and impulsiveness. OCD patients with child ADHD symptoms but not continued symptoms till adulthood versus those without child ADHD symptoms had higher levels of depression, anxiety, and impulsiveness and more severe OCD symptoms.

Conclusion: ADHD in adults with OCD is associated with some features impairing the clinical picture including higher levels of anxiety, depression, and impulsiveness reflecting more chronic illness. A childhood history of ADHD symptoms, even if not continued till adulthood, caused more impulsiveness, more severe OCD symptoms, and more anxiety and depression comorbidity.
\end{abstract}

Keywords: OCD, ADHD, Anxiety, Impulsiveness, Depression

\section{Background}

Attention deficit hyperactivity disorder (ADHD) is described by a long-lasting pattern of hyperactivity and/or inattention and impulsivity. The ADHD symptoms interfere with an anticipated growing level and influence working and advancement and have proceeded to a degree that meddles with a foreseen developing level and affects scholarly, academic, and social or working accomplishments [1]. In a recent meta-analysis of 175 studies, the estimated overall worldwide pooled prevalence was $7.2 \%$ [2]. The prevalence is anticipated to increase with the new diagnostic criteria scheduled in the DSM-5 [1]. While the prevalence gets lower with age, the disorder continues into adulthood in about $40 \%$ of affected children [3].

\footnotetext{
* Correspondence: Lamis_Dahi@yahoo.com

Faculty of Medicine, Zagazig University, Zagazig, Egypt
}

The main features of obsessive-compulsive disorder (OCD) are the presence of compulsive and obsessive behaviors of significant length, greater than an hour per day, generating suffering and discomfort [1]. It appears to be difficult to suppress compulsions or obsessions in those affected with OCD often, although patients usually feel that their compulsions or obsessions are readily irrational [4].

Within the last years, multiple studies identified the comorbidity between ADHD and OCD in pediatric OCD samples [5]. Rates of comorbidities are highly varying, fluctuating from near 0 to $60 \%$ with lower comorbidity rates stated in adults relative to youth trials [6]. Higher degrees of ADHD symptoms have been recorded in OCD, with rates up to $30 \%$ of comorbid ADHD in adolescents and children [7]. As indicated by past investigations held among young people or youngsters with ADHD, close to zero to 7.5\% have OCD [8]. The frequency of ADHD among OCD children or 
adolescents in other studies was stated to be above $20 \%$ [9]. Various studies held to assess OCD prevalence in adults with ADHD have found it to be about 1-13\% [10]. Both disorders, when comorbid, cause the clinical course to be unfavorable, more susceptibility to substance use, and a bad response to treatment. So we have to diagnose and manage ADHD symptoms in OCD patients to improve the outcome of the disorder and patients' quality of life [9].

\section{Objectives}

- To explore childhood symptoms of ADHD in adult OCD patients who had never been diagnosed with ADHD during their childhood

- To compare the levels of impulsiveness, severity of depression, and anxiety between obsessivecompulsive adults having and not having childhood ADHD symptoms

- To compare the same parameters among those who had childhood symptoms of ADHD but not continued symptoms versus those who did not have symptoms since childhood

\section{Methods}

This study is a cross-sectional study. It was done at the Psychiatry Department, Zagazig University hospitals, during the period from February 2018 to February 2019.

\section{Participants}

One hundred OCD patients from both genders (aged 18-45 years), with DSM-5 diagnosis of OCD, who fulfilled the inclusion criteria were chosen from both the inpatient ward and the outpatient clinic by simple random sampling.

\section{Study size}

Assuming that the prevalence of childhood ADHD symptoms in OCD patients is $40 \%$ and the rate of admission is 240 cases/year, so the sample size is calculated by Epi Info 6 will be 100 patients (estimated according to confidence interval; C.I) with the a diagnosis of OCD who fulfill the inclusion criteria and will be recruited by systematic random sampling technique until the sample size is reached.

The study included patients of both genders who met DSM-5 criteria for OCD. Their ages ranged from 18 to 45 (in trial to avoid recall bias, also attention deficit symptoms diminished with aging). Full psychiatric examination was held to exclude patients with a history of any other psychiatric disorder.

\section{Operational design}

This study is a cross-sectional study. This study received ethical committee approval from the Department of Psychiatry, Zagazig University, and written informed consent was obtained.

We applied the following assessment procedures to all subjects:

\section{General Medical Examination:}

General medical examination of patients was done to exclude the presence of inflammation, severe physical disorders or Organic brain disease.

2. The Structured Clinical Interview for DSM-5 (SCID 5) to diagnose OCD [11]

\section{The Hamilton Depression Rating Scale (HDRS)}

Clinician-rated scale administrated in $20-30 \mathrm{~min}$ to assess the severity of, and change in, depressive symptoms in adults. The HDRS (known also as the HAMD) is considered the most worldwide used scale to assess depression. Seventeen items (HDRS17) form the original version referring to symptoms of depression experienced over the last week. The HDRS was used at first for hospital inpatients and so focus on physical and melancholic symptoms. Scoring varies by version. For the HDRS17, the normal range score is from 0 to 7 (or in clinical remission), a moderate severity score begins from 20 or higher [12]. We used the Arabic version [13].

\section{Hamilton Anxiety Rating Scale (HARS)}

It is a clinician-rated scale providing an analysis of anxiety severity. It is scored based on the rating of 40 individually assessed criteria. Scoring of each item based independently on a 5-point scale. Each question (statement) is answered using a Likert scale, the score of each statement ranges between 0 and 4,0 refers to not present in the patient and 4 refers to very severe. A total score is calculated by the summation of each of the 14 items. This calculation will yield a comprehensive score in the range from 0 to 5 [14]. We used the Arabic version [15].

\section{Yale-Brown Obsessive-Compulsive Scale (Y-BOCS)}

This scale is utilized to rate the severity of (OCD) symptoms. This scale, which measures compulsions separately from obsessions, measures explicitly the symptoms' severity of obsessive-compulsive disorder but not being biased about compulsions or obsessions type. It is a self-rating scale containing 10-items; each 
item rated from 0 to 4 according to the severity of symptoms, yielding a total possible scoring from 0 to 40. Questions ask about the time spent on obsessions, how much distress they have, and how much they can control thoughts. Compulsions are asked about the same questions. The results are analyzed according to the total score: sub-clinical scoring is from 0 to 7 , mild is from 8 to 15 , moderate is from 16 to 23 , severe is from 24 to 31 , and extreme is from 32 to 40 [16]. We used the Arabic version [17].

\section{Barratt Impulsiveness Scale, Version 11 (BIS-11)}

The current version of BIS-11 and its predecessors were developed to assess impulsivity. The BIS 11 looks at 3 domains of impulsivity: motor, planning, and attention impulsiveness. The BIS-11 is a selfrating questionnaire with 30 items scored ranging from $1=$ rarely $/$ never to $4=$ almost always/always. The scoring (total impulsivity score) is as follows: 6070 mild, $70-80$ moderate, and if more than or equal 80 then impulsivity is severe. Administration time is not specified yet estimated to be $10-15 \mathrm{~min}$. The test requires a fifth-grade reading level and is intended for individuals ages 8 and older [18]. We used the Arabic version [19].

\section{The Wender Utah Rating Scale for the retrospective assessment of symptoms of childhood ADHD}

The 61 questions were answered by the adult patient remembering his or her behavior during childhood with five possible answers scored from 0 to 4 . The minimum score for 25 questions was 0 and the maximum score was 100 . Forty-six refers to a cut-off score, 86 of the ADHD patients, 99 of the normal persons, and $81 \%$ of depressed individuals were classified correctly [20]. We used the Arabic version [21].

\section{The adult ADHD self-report scale Symptom Checklist}

It is an instrument including 18 criteria based on DSM-IV-TR. The most predictive symptoms of ADHD were found to be within six questions of the eighteen. Part A contained these six questions. The other 12 questions form Part B. If four or more marks appeared in the dark boxes of Part A, this indicates the patient's symptoms to be highly consistent with adult ADHD. Part B scoring can serve as a tool to further understand the patient's symptoms. The six questions consisting Part A are most predictive of the disorder [22]. We used the Arabic version [21].

\section{After collecting data from all participants}

Firstly, to find the frequency of childhood symptoms of ADHD in patients with OCD, among patients with childhood symptoms of ADHD, some with continued symptoms in adulthood, and those who did not, we compared them regarding the severity of depression, anxiety, levels of impulsiveness, and symptom severity.

Also, we compared the same parameters among those who had childhood symptoms of ADHD but not continued symptoms versus those who did not have symptoms since childhood. This was done to assess the effect of childhood symptoms of ADHD even if remitted in adulthood.

\section{Statistical analysis}

Statistical analyses were calculated using version 24 of IBM SPSS Statistics (IBM; Armonk, New York, USA).

Continuous variables were presented as mean \pm SD or median (range).

The presentation of categorical variables was by the frequency and percentage.

Levene's test checked homogeneity of variance.

Shapiro-Wilk test was used to check normality.

Independent samples $t$ test is used to detect the difference between the means of two independent groups on a continuous dependent variable.

Chi-squared test of association can discover the relationship between two categorical variables.

$P$ value $(\leq 0.05)$ was considered a statistically significant difference.

\section{Results}

We found that $44 \%$ of the OCD patients had ADHD since childhood, while the remaining $56 \%$ did not have it at all. From that 44\% (who had child ADHD), 68.2\% of them still have adult ADHD (Figs. 1 and 2).

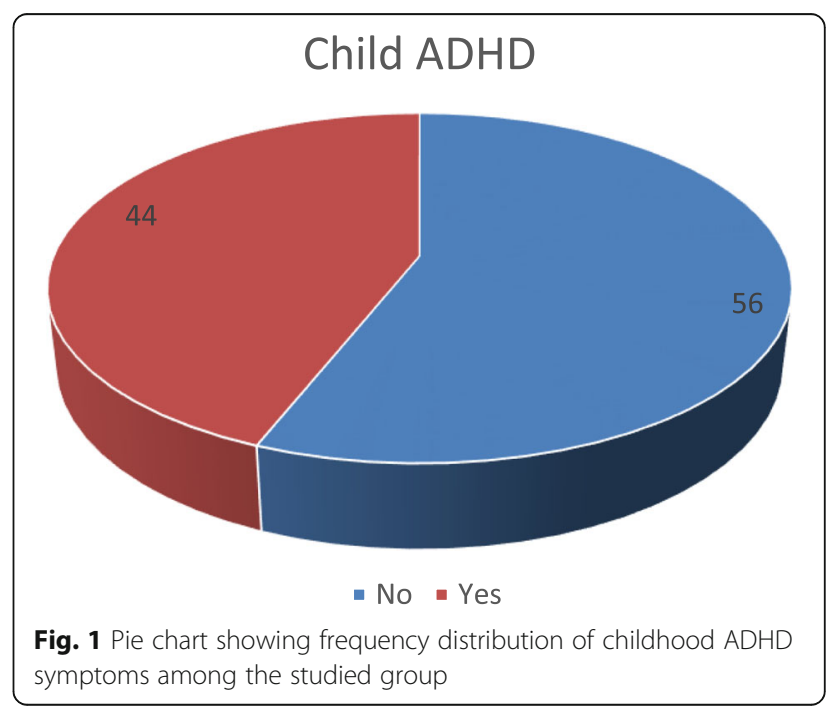




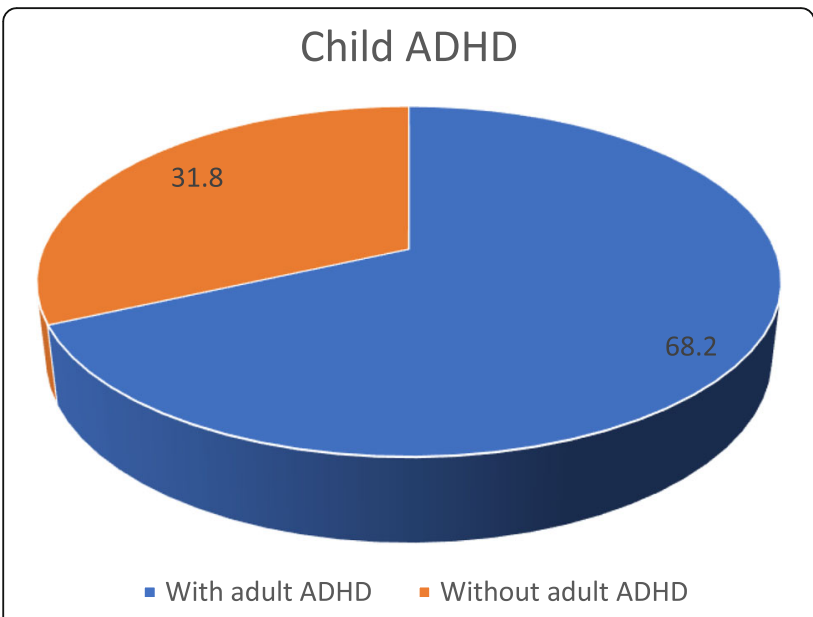

Fig. 2 Pie chart showing frequency distribution of adult ADHD among the studied group

We found that there were significant differences between both groups regarding impulsivity, non-planning and motor subtypes which were found to be significantly higher among patients with adult ADHD when compared to those without adult ADHD (Table 1). There was a non-significant difference between the studied groups regarding HAMD, Y-BOCs, and HARS scores. However, it was noticed that all of them were found to be higher among those with ADHD when compared to those without ADHD (Table 2).

Upon comparing OCD patients without child ADHD symptoms versus those with child ADHD symptoms but not continued symptoms till adulthood, we found that there were significant differences between the studied groups regarding attention. However, the difference between them was non-significant regarding total impulsivity, motor activities, and non-planning that were higher among OCD adults with child ADHD symptoms but not continued symptoms till adulthood (Table 3). We found also that there was a significant difference between the studied groups regarding HARS. However, the difference between them was non-significant regarding Y-BOCs and HAMD scores that were also higher among child ADHD symptoms but not continued symptoms till adulthood (Table 4).

\section{Discussion}

In this study, we explored the childhood symptoms of ADHD in an adult sample of OCD patients. We also compared the levels of impulsiveness, anxiety, and depression between obsessive-compulsive adults (who had a history of child ADHD) having and not having adult ADHD symptoms.

Our results revealed that $44 \%$ of the OCD patients had childhood ADHD symptoms, while the remaining 56\% did not have it at all. From those having had child ADHD symptoms, $68.2 \%$ still had adult ADHD. In other words, about $30 \%$ of OCD patients have adult ADHD.

These results are coincident with previous studies where rates of childhood ADHD among OCD patients were $40 \%$ and $40.9 \%$, respectively [23, 24]. Prevalence of ADHD among those having OCD has ranged between about 40 and $60 \%$ in adolescent and child psychiatry clinic [25], 59\% within a sample of pediatric psychopharmacology clinic [26], 51\% in a child OCD clinic [27], 43\% among the sample of a genetic study in families [28], and $42 \%$ in a specialty clinic of OCD [29].

Our results are coincident with other studies where rates of adult ADHD among OCD patients were 19\% and $23 \%$, respectively [30,31]. This finding confirms the idea that the co-occurring between these disorders continue until adulthood. Our results are higher than the results of previous studies where rates of adult ADHD among OCD patients were $13.7 \%, 13 \%, 8 \%$, and $10 \%$,

Table 1 Impulsivity among those with and without adult ADHD

\begin{tabular}{|c|c|c|c|c|}
\hline Variable & OCD patients without adult ADHD $(n=14)$ & OCD patients with adult ADHD $(n=30)$ & MW & $P$ \\
\hline \multicolumn{5}{|l|}{ Impulsivity } \\
\hline Mean \pm SD & $57.2 \pm 23.1$ & $88.4 \pm 13.5$ & -3.972 & $<0.001(H S)$ \\
\hline Median, range & $51,31-100$ & $92,62-107$ & & \\
\hline \multicolumn{5}{|l|}{ Attention } \\
\hline Mean $\pm S D$ & $21.6 \pm 5.59$ & $22.8 \pm 4.08$ & -0.639 & 0.523 (NS) \\
\hline Median, range & $20,8-28$ & $22,15-30$ & & \\
\hline \multicolumn{5}{|l|}{ Non-planning } \\
\hline Mean \pm SD & $20.4 \pm 11.2$ & $35.2 \pm 6.51$ & -3.678 & $<0.001(H S)$ \\
\hline Median, range & $17,11-40$ & $38,15-42$ & & \\
\hline \multicolumn{5}{|l|}{ Motor } \\
\hline Mean $\pm S D$ & $17.5 \pm 8.11$ & $30.2 \pm 7.10$ & -3.392 & $<0.001(H S)$ \\
\hline Median, range & $16,11-35$ & $32,16-40$ & & \\
\hline
\end{tabular}

$P$ value, NS not significant, $S$ significant, $H S$ highly significant, $S D$ standard deviation, MW Mann Whitney test 
Table 2 Severity of OCD, depression, and anxiety among those with and without adult ADHD

\begin{tabular}{|c|c|c|c|c|}
\hline Variable & OCD patients without adult ADHD $(n=14)$ & OCD patients with adult ADHD $(n=30)$ & MW & $P$ \\
\hline Severity of OCD (Y-BOCs) & & & & 0.658 (NS) \\
\hline Mean \pm SD & $24.7 \pm 8.81$ & $26.3 \pm 9.08$ & -0.442 & \\
\hline Median & 22.5 & 23 & & \\
\hline Range & $12-40$ & $11-40$ & & \\
\hline Depression (HAMD) & & & & 0.369 (NS) \\
\hline Mean \pm SD & $18.5 \pm 10.8$ & $21.3 \pm 8.78$ & -0.898 & \\
\hline Median & 15 & 18 & & \\
\hline Range & $9-38$ & $10-38$ & & \\
\hline Anxiety (HARS) & & & & 0.235 (NS) \\
\hline Mean \pm SD & $24.6 \pm 14.3$ & $29.5 \pm 13.1$ & -1.187 & \\
\hline Median & 26.5 & 28 & & \\
\hline Range & $9-50$ & $12-50$ & & \\
\hline
\end{tabular}

respectively [32-35]. They used different sample characteristics with different age ranges (18-80).

\section{Regarding impulsivity scores}

There is a highly significant difference between (childhood ADHD symptoms + OCD) patients with adult ADHD and without regarding total impulsivity, nonplanning, and motor subtypes which were found to be significantly higher among patients with adult ADHD when compared to those without adult ADHD. However, there is a non-significant difference between the studied groups regarding attentional subtype.

Our results are consistent with another study that found patients with ADHD and OCD had significantly higher total, attentional, and motor subscale scores of BIS-11 compared with pure OCD patients. Particularly, total scores of BIS-11 were strongly associated with comorbid diagnosis of OCD and ADHD [36]. Another study found that there were significant correlations between the attentional subscores of BIS-11 and total obsession and compulsion subscale scores of Y-BOCS among OCD patients [37]. Therefore, our findings might suggest that attentional impulsivity scores are higher regardless of childhood ADHD symptoms continued into adulthood or not. Therefore, impulsivity might be one of the significant indicators of comorbidity between OCD and ADHD.

Upon comparing OCD patients without child ADHD symptoms and those with child ADHD symptoms but not continued symptoms till adulthood, we found that there were significant differences between the studied groups regarding attentional and motor impulsivity. However, the difference between them was non-significant regarding total impulsivity and non-planning which was found to be higher among patients with child ADHD symptoms when compared

Table 3 Relationship between impulsivity in those without child ADHD and those with child and adult ADHD

\begin{tabular}{|c|c|c|c|c|}
\hline Variable & OCD without child ADHD $(n=56)$ & OCD with child without adult ADHD $(n=14)$ & MW & $P$ \\
\hline \multicolumn{5}{|l|}{ Impulsivity } \\
\hline Median & 43.5 & 51 & -1.059 & 0.290 (NS) \\
\hline Range & $32-112$ & $31-100$ & & \\
\hline \multicolumn{5}{|l|}{ Attention } \\
\hline Median & 14.5 & 20 & -2.699 & $0.007(S)$ \\
\hline Range & $8-30$ & $8-28$ & & \\
\hline \multicolumn{5}{|c|}{ Non-planning } \\
\hline Median & 14.5 & 17 & -0.458 & 0.647 (NS) \\
\hline Range & $11-42$ & $11-40$ & & \\
\hline \multicolumn{5}{|l|}{ Motor } \\
\hline Median & 13 & 16 & -0.266 & 0.790 (NS) \\
\hline Range & $10-40$ & $11-35$ & & \\
\hline
\end{tabular}


Table 4 Relationship between severity of OCD, depression, anxiety, and child ADHD among the studied groups

\begin{tabular}{|c|c|c|c|c|}
\hline Variable & OCD without child ADHD $(n=56)$ & OCD with child without adult ADHD $(n=14)$ & MW & $P$ \\
\hline \multicolumn{5}{|c|}{ Severity of OCD (Y-BOCs) } \\
\hline Median & 24 & 33 & -1.594 & 0.111 (NS) \\
\hline Range & $9-40$ & $16-38$ & & \\
\hline \multicolumn{5}{|c|}{ Depression (HAMD) } \\
\hline Median & 17 & 32 & -0.562 & 0.547 (NS) \\
\hline Range & $8-37$ & $9-35$ & & \\
\hline \multicolumn{5}{|c|}{ Anxiety (HARS) } \\
\hline Median & 26.5 & 48 & -3.100 & $0.002(S)$ \\
\hline Range & $9-50$ & $12-50$ & & \\
\hline
\end{tabular}

to those without adult ADHD. All of this indicates that a history of ADHD symptoms, even not continued till adulthood, causes higher impulsivity scores. Up to our knowledge, no previous studies discussed this finding.

\section{Regarding depression and anxiety scores}

It was noticed that depression and anxiety scores were found to be higher but not significant among (childhood ADHD symptoms + OCD) patients with adult ADHD when compared to those without. We agree with a previous study that found OCD patients with comorbid ADHD presented more severe anxiety symptoms. The comorbidity between OCD and anxiety symptoms has been demonstrated over the years, with some papers reporting that anxiety disorders are the most frequent comorbid conditions in OCD [38], with frequencies that range from 62 [39] to $75.8 \%$ [30].

We disagree with the findings of previous studies that found that subjects with OCD had other mental disorders, mainly anxiety disorders (generalized anxiety disorder, social phobia, simple phobias, panic disorder, and separation anxiety disorder), confirming that those disorders are much more co-occurring in childhood and adolescence [40, 41]. However, this high co-occurrence was not affected by ADHD comorbidity. Our results are additionally conflicting with other research that found that no patient with OCD plus ADHD had depressive or anxiety disorders [42].

We found that there was a noteworthy contrast with regards to HARS which was observed to be higher among patients with child ADHD symptoms not continued till adulthood versus those without child ADHD manifestations. The difference was non-significant as regards the HAMD scores which were observed to be higher among patients with child ADHD symptoms not continued till adulthood. All of this indicates that the history of ADHD symptoms, even not continued until adulthood, causes more anxiety and depression comorbidity. As indicated by our insight, no past papers examined these discoveries.

\section{Regarding the severity of OCD}

There is a non-significant difference between (childhood ADHD symptoms +OCD) patients with adult $\mathrm{ADHD}$ and without regarding $\mathrm{Y}$-BOCs scores.

According to a previous study, no significant differences were noticed between the OCD with ADHD and $\mathrm{OCD}$ without $\mathrm{ADHD}$ groups regarding mean YBOCS compulsion, obsession, and total scores [23]. Another investigation compared the OCD patients with and without adulthood ADHD in terms of several clinical and demographic variables. They found that both groups did not differ greatly in the current OCs severity [42]. Our outcomes are conflicting with a past report that discovered higher total and obsession severity according to the Y-BOCS among OCD adults comorbid with ADHD [35].

We found that Y-BOCs scores were higher but not significant among patients with child ADHD symptoms but not continued symptoms till adulthood versus those without child ADHD symptoms. According to our knowledge, no previous papers discussed this finding.

\section{Limitations}

This study is a cross-sectional study, which eliminates the causal efficacy of all data; therefore, we can only infer the direction of the association between trait ADHD and OCD. The current study is sensitive to recall bias. The good psychometric properties of the WURS may somewhat balance this limitation. The sample size of the study was small, especially when dividing into groups. There was no healthy control group in this study, and such reports among the general population may get similar results found in the patients with OCD. 


\section{Conclusion}

Childhood ADHD symptoms are experienced by a significant number of patients in this sample. ADHD in adults with OCD is associated with some features impairing the general clinical picture including higher levels of anxiety and impulsiveness reflecting a more chronic illness. A childhood history of ADHD symptoms, even not continued till adulthood, causes more impulsiveness, more severe OCD symptoms, and more anxiety and depression comorbidities. Our study suggests that childhood ADHD symptoms need more attention in psychiatric clinical practice and scientific research

\section{Abbreviations}

ADHD: Attention deficit hyperactivity disorder; BIS-11: Barratt Impulsiveness Scale, Version 11; HAMD/HDRS: The Hamilton Depression Rating Scale; HARS: Hamilton Anxiety Rating Scale; IRB: Institutional Review Board; OCD: Obsessive-compulsive disorder; SPSS: Statistical Package for the Social Sciences; WURS: The Wender Utah Rating Scale; Y-BOCS: Yale-Brown Obsessive-Compulsive Scale

\section{Acknowledgements}

Not applicable

\section{Authors' contributions}

WA designed the study. AF analyzed and interpreted the patient data. NR contributed to writing the manuscript. LI collected the patients' data and applied the scales. All authors read and approved the final manuscript.

\section{Funding}

The authors declare that they have no competing financial interests.

\section{Availability of data and materials}

Available upon request

\section{Ethics approval and consent to participate}

Approval was obtained from the Institutional Review Board (IRB), Ethics Committee of the Psychiatry Department, Zagazig University (reference number is 3848)

Written informed consent was obtained from participants after discussing with them the aim of the study.

\section{Consent for publication}

Not applicable

\section{Competing interests}

The authors declare that they have no competing interests.

Received: 29 July 2019 Accepted: 2 October 2019

Published online: 06 January 2020

\section{References}

1. American Psychiatric Association (2013) Diagnostic and statistical manual of mental disorders. American Psychiatric Association, Arlington

2. Thomas R, Sanders S, Doust J, et al. (2015) Prevalence of attention-deficit/ hyperactivity disorder: a systematic review and meta-analysis. Pediatrics;135: e994-1001. DOl: https://doi.org/10.1542/peds.2014-3482

3. Biederman J, Mick E, Faraone SV et al (2000) Age-dependent decline of symptoms of attention deficit hyperactivity disorder: impact of remission definition and symptom type. Am J Psychiatry 157:816-818. https://doi.org/ 10.1176/appi.ajp.157.5.816

4. American Psychiatric Association (1994) Diagnostic and statistical manual of mental disorders, 4rth edn. American Psychiatric Association, Washington, DC

5. Abramovitch, A., Dar, R, Mittelman A., and Wilhelm, S. (2015).Comorbidity between attention-deficit hyperactivity disorder and obsessive-compulsive disorder across the lifespan: a systematic and critical review. Harv Rev Psychiatry. 2015 Jul-Aug;23(4):245-262. DOl: https://doi.org/10.1097/HRP. 0000000000000050

6. Abramovitch A, Dar R, Mittelman A, Schweiger A. (2013) Don't judge a book by its cover: ADHD-like symptoms in obsessive-compulsive disorder. J Obsessive Compuls Relat Disord;2:53-61. .doi.org/https://doi.org/10.1016/j. jocrd.2012.09.001

7. March JS, Leonard HL (1996) Obsessive-compulsive disorder in children and adolescents: a review of the past 10 years. J Am Acad Child Adolesc Psychiatry 35:1265-1273. https://doi.org/10.1097/00004583199610000-00012

8. Lee SS, Falk AE, Aguirre VP (2012) Association of comorbid anxiety with social functioning in school-age children with and without attention-deficit/ hyperactivity disorder (ADHD). Psychiatry Res 197:90-96. https://doi.org/10. 1016/j.psychres.2012.01.018 Epub 2012 Mar 26

9. De Mathis MA, Diniz JB, Hounie AG, Shavitt RG, Fossaluza V, Ferrã Y et al (2013) Trajectory in obsessive-compulsive disorder comorbidities. Eur Neuropsychopharmacol 23:594-601. https://doi.org/10.1016/j.euroneuro. 2012.08.006 Epub 2012 Aug 22

10. Wilens TE, Biederman J, Faraone SV, Martelon M, Westerberg D, Spencer TJ (2009) Presenting ADHD symptoms, subtypes, and comorbid disorders in clinically referred adults with ADHD. J Clin Psychiatry 70:1557-1562. https:// doi.org/10.4088/JCP.08m04785pur

11. First, M. B. (2014). Structured clinical interview for the DSM (SCID). The encyclopedia of clinical psychology, 1-6.

12. Hamilton M. (1960) A rating scale for depression. J Neurol Neuro-surgery Psychiatry; 23:56 - 62. DOI: https://doi.org/10.1136/jnnp.23.1.56

13. Fateem, L. (1998). Hamilton depression rating scale (Arabic translation). Cairo, Egypt: The Anglo Egyptian Bookshop.

14. Hamilton M (1959) The assessment of anxiety states by rating. Br J Med Psychol 32:50-55

15. Fateem, L. (1998). Hamilton anxiety rating scale (Arabic translation). Cairo, Egypt: The Anglo Egyptian Bookshop.

16. Goodman WK, Price LH, Rasmussen SA, Mazure C, Fleischmann RL, Hill CL et. al, (1989) The Yale-Brown Obsessive-Compulsive Scale: measures of internal consistency. Psychiatry Res; Volume 51, Issue 2, February 1994, Pages 203-211

17. Okasha A, Saad A, Khalil AH, El Dawla AS, Yehia N (1994) Phenomenology of obsessive-compulsive disorder: a transcultural study. Compr Psychiatry 35: 191-197

18. Patton JH, Stanford MS, Barratt ES. Factor structure of the Barratt impulsiveness scale (1995). Clin Psychol.; Nov;51(6):768-774.

19. Rafei H, Ghanem M, Gamaluddin H, et al. (2009): Psychiatric assessment of cases with self-Inflicted poisoning in a sample of Egyptian children and adolescents. MD Thesis in psychiatry Ain shams University.

20. Wender PH (1995) Attention-deficit hyperactivity disorder in adults. New York, NY: Oxford University Press.

21. Abdelkarim A, Salama H, Ibrahim S, Abou El Magd O (2015) The prevalence and characteristics of attention-deficit hyperactivity disorder among a sample of Egyptian substance-dependent inpatients. Egypt J Psychiatry 2015(36):9-13

22. Daigre BC, Ramos-Quiroqa JA, Valero S, Bosch R, Roncero C et al (2009) Adult ADHD Self Report Scale-V1.1 (ASRS-V1.1) symptom checklist in patients with substance use disorders. Actas Eso Psiquiatr 37:299-305

23. Çelebi F., Koyuncu A., Ertekin E., Alyanak B., and Tükel R. (2016). The features of comorbidity of childhood ADHD in patients with obsessive-compulsive disorder. Journal of Attention Disorders; 1 -8. DOl:https://doi.org/10.1177/ 1087054716669228

24. Tan O, Metin B, Metin S (2016) Obsessive-compulsive adults with and without childhood ADHD symptoms. ADHD Atten Def Hyp Disord; ep 8(3): 131-138. https://doi.org/10.1007/s12402-016-0196-3 Epub 2016 Apr 7

25. Coskun M, Zoroglu S, Ozturk M (2012) Phenomenology, psychiatric comorbidity and family history in referred preschool children with obsessive-compulsive disorder. Child Adolesc Psychiatry Ment Health 6(1): 36. https://doi.org/10.1186/1753-2000-6-36

26. Geller D, Biederman J, Faraone SV, Frazier J, Coffey BJ, Kim G et al (2000) Clinical correlates of obsessive-compulsive disorder in children and adolescents referred to specialized and non-specialized clinical settings. Depress Anxiety 11:163-168. https://doi.org/10.1002/1520-6394

27. Geller DA, Biederman J, Faraone S, Agranat A, Cradock K, Hagermoser L et a (2001) Developmental aspects of obsessive-compulsive disorder: findings in children, adolescents, and adults. J Nerv Ment Dis 189:471-477 
28. Joshi G, Wozniak J, Petty C, Vivas F, Yorks D, Biederman J et. al. (2010) Clinical characteristics of comorbid obsessive-compulsive disorder and bipolar disorder in children and adolescents. Bipolar Disord; 12:185-195 DOl: https://doi.org/10.1111/j.1399-5618.2010.00795.x.

29. Geller DA, Wieland N, Carey K, Vivas F, Petty CR, Johnson J et al (2008) Perinatal factors affecting the expression of obsessive-compulsive disorder in children and adolescents. J Child Adolesc Psychopharmacol 18:373-379. https://doi.org/10.1089/cap.2007.0112

30. Ruscio A, Stein D, Chiu W, Kessler R (2010) The epidemiology of obsessivecompulsive disorder in the National Comorbidity Survey Replication. Mol Psychiatry 15:53-63. https://doi.org/10.1038/mp.2008.94 Epub 2008 Aug 26

31. Anholt GE, Cath DC, van Oppen P et al (2010) Autism and ADHD symptoms in patients with OCD: are they associated with specific OC symptom dimensions or OC symptom severity? J Autism Dev Disord 40:580-589. https://doi.org/10.1007/s10803-009-0922-1

32. Mancebo MC, Garcia AM, Pinto A et al (2008) Juvenile-onset OCD: clinical features in children, adolescents, and adults. Acta Psychiatr Scand 118:149159. https://doi.org/10.1111/j.1600-0447.2008.01224.x

33. Frost RO, Steketee G, Tolin DF (2011) Comorbidity in hoarding disorder. Depress Anxiety 28:876-884. https://doi.org/10.1002/da.20861 Epub 2011 Jul 18

34. De Mathis MA, Diniz J, Hounie A et al (2013) Trajectory in obsessivecompulsive disorder comorbidities. Eur Neuropsychopharmacol 23:594-601. https://doi.org/10.1016/j.euroneuro.2012.08.006 Epub 2012 Aug 22

35. Blanco-Vieira T., Santos M., . Ferrão Y. A , Torres A. R., Miguel E. C., Bloch M. H. et al, (2019) The impact of attention deficit hyperactivity disorder in obsessive-compulsive disorder subjects. Depress Anxiety; 36(6):533-542. DOI: https://doi.org/10.1002/da.22898. Epub 2019 Apr 16.

36. Mersin Kilic S., Dondu A., Memis C. O., Ozdemiroglu F., and Sevincok L. (2016) The clinical characteristics of ADHD and obsessive-compulsive disorder comorbidity. Journal of Attention Disorders 1 -7 DOl.org/https:// doi.org/10.1177/1087054716669226

37. Ettelt S, Ruhrmann S, Barnow S, Buthz F, Hochrein A, Meyer K et al (2007) Impulsiveness in obsessive-compulsive disorder: results from a family study. Acta Psychiatrica Scandinavica 115:41-47. https://doi.org/10.1111/j.16000447.2006.00835.x

38. Diniz JB, Miguel EC, Oliveira ARD, Reimer AE, Brandão ML, Mathis MAD et al (2012) Outlining new frontiers for the comprehension of obsessivecompulsive disorder: a review of its relationship with fear and anxiety. Revista Brasileira de Psiquiatria 34:81-91

39. Torres AR, Prince MJ, Bebbington PE, Bhugra D, Brugha TS, Farrell M et al (2006) Obsessive-compulsive disorder: Prevalence, comorbidity, impact, and help-seeking in the British National Psychiatric Morbidity Survey of 2000. Am J Psychiatry 163(11):1978-1985

40. Masi G, Millepiedi S, Mucci M, Bertini N, Pfanner C, Arcangeli F (2006) Comorbidity of obsessive-compulsive disorder and attention-deficit/ hyperactivity disorder in referred children and adolescents. Comprehensive Psychiatry 47(1):42-47. https://doi.org/10.1016/j.comppsych.2005.04.008

41. Masi G, Perugi G, Toni C, Millepiedi S, Mucci M, Akiskal HS (2004) Obsessivecompulsive-bipolar comorbidity: focus on children and adolescents. J Affect Disord 78:175-183. https://doi.org/10.1016/S0165-0327(03)00107-1

42. Walitza S, Zellmann H, Irblich B, Lange KW, Tucha O, Hemminger $\mathrm{U}$ et al (2008) Children and adolescents with obsessive-compulsive disorder and comorbid attention-deficit hyperactivity disorder: preliminary results of a prospective follow-up study. J Neural Transm 115:187-190. https://doi.org/ 10.1007/s00702-007-0841-2 Epub 2008 Jan 16

\section{Publisher's Note}

Springer Nature remains neutral with regard to jurisdictional claims in published maps and institutional affiliations.

\section{Submit your manuscript to a SpringerOpen ${ }^{\circ}$ journal and benefit from:}

- Convenient online submission

- Rigorous peer review

- Open access: articles freely available online

- High visibility within the field

- Retaining the copyright to your article

Submit your next manuscript at $\boldsymbol{\sim}$ springeropen.com 